\title{
PERSPECTIVA KUHNIANA SOBRE A CIÊNCIA CONTÁBIL: DO SURGIMENTO DO PARADIGMA AO PERÍODO DE CRISE
}

\author{
KUHNIAN PERSPECTIVE ON THE ACCOUNTING SCIENCE: FROM THE \\ EMERGENCE OF PARADIGM TO THE PERIOD OF CRISIS
}

\author{
RAFAEL SOUSA LIMA \\ Universidade de Brasília. Endereço: Campus Darcy Ribeiro, Prédio da \\ FACE | Asa Norte | 70910-900 | Brasília/DF | Brasil. \\ (1) http://orcid.org/0000-0001-5385-4278 \\ rafaellima1515@gmail.com
}

\section{ANDRÉ LUIZ MARQUES SERRANO}

Universidade de Brasília. Endereço: Campus Darcy Ribeiro, Prédio da FACE | Asa Norte | 70910-900 | Brasília/DF | Brasil.

(D) http://orcid.org/0000-0001-5182-0496

andrelms.unb@gmail.com

\section{LUCAS OLIVEIRA GOMES FERREIRA}

Universidade de Brasília. Endereço: Campus Darcy Ribeiro, Prédio da FACE | Asa Norte | 70910-900 | Brasília/DF | Brasil.

(1) http://orcid.org/0000-0002-8734-4740

lucasogf@gmail.com

\section{RESUMO}

O objetivo deste trabalho é discutir a ciência contábil do ponto de vista da teoria Kuhniana. O estudo enquadra-se como ensaio teórico, em que se busca, com base em pesquisa bibliográfica, expor ideias e refletir sobre conceitos. Para tanto, apresenta-se ao leitor breve contexto histórico sobre o desenvolvimento do conhecimento contábil, mostrando as transformações pelas quais passou esse campo de estudo e a sua busca pelo amadurecimento enquanto ciência, seja normativa ou positiva. Também são analisadas as características do processo científico kuhniano, abordando-se as fases de formação de uma ciência e de seus paradigmas. Assim, propõe-se uma estrutura kuhniana para a ciência contábil, tendo como foco os séculos XX e XXI, com enquadramento da obra A Statement of Basic Accounting Theory (AAA, 1966) como marco inicial do (novo) período científico da contabilidade. Ainda, foram analisados aspectos relacionados às estruturas conceituais, apontando-se críticas ao framework vigente. Por fim, sustenta-se que a contabilidade vive um período de crise enquanto ciência, pois seu paradigma estaria em "xeque" ao não mais oferecer soluções às questões emergentes do campo, abrindo-se oportunidade para um novo paradigma contábil baseado em tecnologia. Como sugestão para pesquisas futuras, indica-se uma abordagem multidisciplinar na contabilidade com a introdução de técnicas de Big Data na produção do conhecimento contábil.

Palavras-chave: Ciência. Paradigma. Kuhn. Estrutura Conceitual. Big Data. 


\begin{abstract}
The work aims to discuss accounting science from the point of view of Kuhnian theory. The study fits as a theoretical essay, in which, based on bibliographic research, to expose ideas and reflect on concepts. To this end, a brief historical context is presented to the reader on the development of accounting knowledge, showing the transformations that this field of study has undergone and its search for maturity as a science, whether normative or positive. The characteristics of the Kuhnian scientific process are also analyzed, addressing the phases of the formation of a science and its paradigms. Thus, a Kuhnian structure for accounting science is proposed, focusing on the 20th and 21st centuries, framing the work A Statement of Basic Accounting Theory (AAA, 1966) as the starting point of the (new) scientific accounting period. Still, aspects related to conceptual frameworks were analyzed, pointing out criticisms to the current framework. Finally, it is maintained that accounting is experiencing a period of crisis as a science, as its paradigm would be in "check" by no longer offering solutions to emerging issues in the field, opening up the opportunity for a new technology-based accounting paradigm. As a suggestion for future research, a multidisciplinary approach to accounting is indicated with the introduction of Big Data techniques in the production of accounting knowledge.
\end{abstract}

Keywords: Science. Paradigm. Kuhn. Conceptual framework. Big Data.

\title{
1 INTRODUÇÃO
}

Chalmers (1993) explica que o filósofo Francis Bacon é tido como um dos pioneiros na discussão do tema método na ciência moderna. O autor esclarece que o referido filósofo, no começo do século XVII, defendia que a ciência tinha como meta melhorar a vida do homem, o que seria possível por meio da coleta de fatos com observação organizada e, a partir disso, derivação de teorias que explicassem o mundo. Dessa forma, o conhecimento científico seria fruto, rigorosamente, da obtenção de dados de uma experiência adquiridos por observação e experimento. Esse entendimento se tornou popular durante a revolução científica que se iniciou à época, motivada por cientistas como Galileu e Newton.

Para Hopwood (2007), no século passado, a contabilidade se valia de uma orientação multidisciplinar (finanças, economia, estatística, psicologia e organização social), sendo que a contabilidade não seria exatamente uma ciência, mas uma prática. Williams (2017) faz um paralelo com o campo da agricultura, no qual houve a implantação de metodologia científica para o desenvolvimento de plantas e animais "melhores", a fim de aperfeiçoar a prática da agricultura, o que levou a disciplinas que são legitimamente descritas como ciências agrícolas ou agronomia. Nesse sentido, o pesquisador acredita que a contabilidade possa ter se desenvolvido de maneira semelhante, embora, talvez, com maior dificuldade.

Já Whitley (1986) explica que, após a Segunda Guerra Mundial, a estratégia de cientificação de uma disciplina voltada para a prática era se tornar um tipo de ciência social aplicada, muito embora Chalmers (1993) defenda que as categorias gerais de ciência e de método científico são usadas indevidamente para excluir ou suprimir áreas de estudo. Dessa forma, sustenta Chalmers (1993), muitas áreas de estudo são consideradas, por seus "advogados", como ciência numa tentativa de ressaltar que os procedimentos e técnicas empregados são tão comprovados como os de uma ciência tradicional como a física. Entretanto o pesquisador afirma que esse entendimento é inapropriado, não cabendo classificar diferentes áreas do conhecimento em um único modelo. Cada campo de estudo precisaria ser analisado individualmente, considerando seus objetivos próprios, os meios utilizados para atingi-los e os resultados alcançados. 
Para Kuhn (1962), o desenvolvimento da ciência se dá por meio de revoluções, e não meramente por acumulação de conhecimento. O conceito-chave no modelo de desenvolvimento científico proposto por Kuhn é o de paradigma. O filósofo, com formação primária em física, considerava que o termo "paradigma" representava as realizações científicas universalmente reconhecidas, em algum período de tempo, quando eram propostos problemas e soluções para uma comunidade de cientistas. Durante a vigência de um paradigma, a ciência experimentava um crescimento acumulativo. Mas, quando um paradigma deixava de oferecer soluções às questões emergentes da área, surgiam novos paradigmas que substituíam o anterior, mas não sem conflitos, razão pelo qual o autor chamava essa transformação de revolução.

Com base na teoria Kuhniana, Mouck (1993) buscou explicar a transformação ocorrida na contabilidade com a evolução dos relatórios financeiros, os quais migraram de uma esfera econômica para a esfera informacional. Para o autor, o paradigma informacional da contabilidade, na essência, seria um subparadigma econômico. Nesse sentido, esclarece o pesquisador, a Hipotése de Mercado Eficiente e o Capital Asset Pricing Model desenvolvidos após a década de 1960 poderiam ser percebidos como ferramentas de expansão do paradigma econômico na contabilidade, e não como uma revolução kuhniana.

Por sua vez, Souza e Beuren (2008) pesquisaram o uso da Teoria Kuhniana em artigos da área contábil. Os pesquisadores localizaram 62 publicações no período de 1966 a 2006 (sendo 39 artigos no período de 1995 e 2006) que mencionavam a obra de Kuhn (1962) nas referências bibliográficas. Contudo, para os autores, a maioria dos trabalhos apresentava uma "apropriação incidental" do tema, pois a menção à teoria kuhniana era superficial e complementar.

Nesse contexto, o objetivo deste trabalho é discutir a ciência contábil do ponto de vista da teoria Kuhniana. A pesquisa foi construída como um ensaio teórico, sustentada com base em pesquisa bibliográfica, com exposição lógica e reflexiva de ideias, buscando discutir, dentro de um linha cronológica, a ciência contábil pela perspectiva kuhniana, especificamente nos séculos XX e XXI. Claro, o assunto enseja maior aprofundamento, não sendo escopo desta pesquisa contrapor paradigmas ou estudos anteriores, mas sim oferecer considerações de caráter reflexivo, cujas limitações são claramente perceptíveis. Ainda, cita-se Iudicibus (2007, p. 10): "Não se pretende redefinir a ciência contábil. Da mesma forma que a Economia é a ciência da escassez, a Contabilidade continua sendo a ciência do patrimônio (e, portanto, da escassez)".

Para tanto, o texto está segregado em seis seções, iniciando-se por esta introdução. Na segunda, são apresentados trechos da história que marcaram o desenvolvimento do conhecimento contábil. Na terceira, apresentam-se as características do processo científico na visão de Kuhn (1962). Por sua vez, na quarta seção, são discutidos aspectos da contabilidade sob o prisma da estrutura da revolução científica kuhniana, apontando-se o surgimento do paradigma e o atual período de crise. A quinta seção trata de nova perspectiva para a contabilidade com a tecnologia. Considerações finais são apresentadas na última seção.

\section{CONHECIMENTO CONTÁBIL}

O conhecimento contábil surgiu há muito tempo. De acordo com a American Institute of Certified Public Accountants (AICPA) (2012), há registros contábeis que remetem à civilização mesopotâmica. Estudos apontam o uso de técnicas contábeis em sociedade antigas do Egito, da Babilônia, da Grécia e de Roma, dois mil anos a.C. (Littleton, 1933 citado por Kam, 1990). Na visão de Williams (2017), o conhecimento contábil se desenvolveu ao longo do tempo. Para o autor, o propósito contábil era acompanhar a evolução da atividade comercial e o crescente número de relacionamentos, apontando quem deve o quê a quem e o que pertence a cada um.

No século XIV, com a expansão do comércio, apareceram os primeiros livros comerciais de contabilidade pelo método das partidas dobradas. Os mercadores italianos Rinieri Fini \& Brothers (entre 1296 a 1305) e Giovani Farolfi \& Co (1299 a 1300) relacionavam o lucro como um aumento no patrimônio líquido e faziam a mensuração para determinado período contábil. 
Mas foi com a publicação do livro Summa de arithmetica, geometrica, proportioni et proportionalitá, em 1494, que o método das partidas dobradas foi consolidado. A obra de Luca Bartolomeo de Pacioli teve tiragem inicial de dois mil exemplares e foi um sucesso editorial para sua época, sendo o livro de matemática mais lido na Itália por um século. Além disso, teve traduções, cópias e adaptações em diversas línguas (Gleeson-White, 2012).

Um pouco mais à frente na história, em 1916, surge nos Estados Unidos a American Accounting Association (AAA), entidade criada com objetivo de discutir assuntos de interesse da área contábil (AAA, 2018). Após a crise de 1929, visando fortalecer a imagem da profissão e diminuir a insegurança no ambiente financeiro decorrente da tensão no mercado de ações norteamericano, a associação publicou vários Statements e manifestos. Basu (2012) explica que a profissão contábil necessitou buscar princípios que sustentassem as práticas contábeis, o que provocou o surgimento de teorias acadêmicas normativas na primeira metade do século passado.

De acordo com a AAA (2018), um dos primeiros documentos publicado por aquela associação foi intitulado A Tentative Statement of Accounting Principles Affecting Corporate Reports, de 1936, que teve por objetivo emitir uma declaração provisória de princípios que deveriam fundamentar e direcionar a elaboração de relatórios financeiros corporativos. $\mathrm{Na}$ sequência, foram editadas e publicadas outras obras, como An introduction to corporate accounting standards, em 1940, de Paton e Littleton, e Structure of accounting theory, em 1953, de Littleton.

Pierson (1959) explica que, após a Primeira Guerra Mundial, houve maior procura por cursos de administração e negócios nos EUA, movimento que foi fomentado pelas instituições Carnegie Corporation e Ford Foundation. Para o autor, três pilares formavam a base para esse desenvolvimento: valores humanos-sociais, métodos quantitativos e aspectos comportamentais. Já Khurana, Kimura e Fourcade (2011) comentam que a Fundação Ford buscou tornar as escolas norte-americanas de negócios mais rigorosas no que se tratava de pesquisa e ensino, promovendo ideologias econômicas e quantitativas. Khurana et al. (2011) afirmam que, no período de 19561964, a Fundação Ford doou a cinco escolas de finanças (Havard, Chicago, Stanford, Columbia e Carnegie Tech's GSIA) cerca de 14,4 milhões de dólares a fim de fomentar a pesquisa e o ensino. Os autores explicam que o objetivo da fundação era financiar pesquisas com aplicação de métodos estatísticos, quantitativos e matemáticos, o que resultou na recomendação de uso de conhecimentos econômicos como forma de melhorar a qualidade e elevar o status das escolas de negócios.

Percebeu-se que as escolas responderam enfatizando análises estatísticas e modelos matemáticos, inclusive com habilidades de abstração e descontextualização, o que se refletiu no perfil das publicações em top journals (Chua, 1996). Basu (2012) aponta que essa iniciativa resultou em novas abordagens e algum sucesso nas décadas de 1960 e 1970, inclusive com a criação, em 1963, do periódico Journal of Accounting Research, da Universidade de Chicago, para dar publicidade às novas pesquisas (quantitativas) em contabilidade.

Nesse contexto de novas pesquisas quantitativas publicadas pelo Journal of Accounting Research, pode-se mencionar Ball e Brown (1968), com estudo relacionando à informação contábil (especialmente o lucro) com o mercado de capitais por meio da avaliação do conteúdo informacional dos relatórios anuais de contabilidade; e Beaver (1968), pesquisador que estudou como os investidores percebiam o valor informacional contido nos lucros, uma vez que havia questionamento quanto à utilidade do lucro na tomada de decisão no mercado de capitais. Para Mouck (1993), esses trabalhos foram essencialmente uma extensão do campo econômico, demonstrando como os pesquisadores de contabilidade poderiam aproveitar o potencial do paradigma da economia financeira.

Na visão de Williams (2017), o repentino sucesso do periódico Journal of Accounting Research foi reflexo da doutrina econômico-positiva que colonizou a academia de contabilidade dos Estados Unidos à época. Christenson (1983) explica que a Escola de Economia de Chicago teve forte influência na contabilidade, especialmente na Rochester School, instituição na qual 
Watts e Zimmerman iniciaram estudos sobre a Teoria Positiva em Contabilidade ao final da década de 1970 (Watts \& Zimmerman, 1986). Whittington (1987) explica que o viés quantitativo também estava presente nas pesquisas de Watts e Zimmerman, ressaltando que esses pesquisadores foram os fundadores do periódico The Journal of Accounting and Economics, revista que focava as pesquisas quantitativas em contabilidade.

Em que pese o entendimento de Sá (2005) no sentido de que é possível compreender os fenômenos contábeis como análogos aos da Física, Química e Biologia, na opinião de Whittington (1987), Whitley (1988) e Hartmann (2017), os artigos acadêmicos no campo da contabilidade se transformaram em um produto incompreensível para a maioria das pessoas, alienadas pelo excessivo foco na matemática, deixando se perder a identidade da contabilidade e tornando-a um sub-ramo da matemática. Tal quadro seria agravado pelo fato de a contabilidade ser uma ciência social, a qual se utiliza de termos abstratos (em contraste com as ciências naturais) e sobre os quais a matemática teria pouco a contribuir.

Chalmers (1993) pondera que não há dúvida de que parte dos pesquisadores enxerga o mundo por meio de algarismos matemáticos, como se todas as áreas do conhecimento pudessem ser aprisionadas por barras de aço, com clara limitação aos métodos (infrutíferos) que muitos se empenham em seguir. Nesse sentido, Basu (2012) defende que a contabilidade imitou um falso modelo, sendo que os cientistas sociais estudam fenômenos consideravelmente mais complexos do que os físicos, em que fazer predições com acurácia similar à ciência natural é bem mais difícil.

Embora se tenha iniciado um processo de transição do normativismo para o positivismo na década de 1960, Silva, Niyama e Noriller (2018) afirmam que nesse período houve grandes mudanças no que concerne à teoria da contabilidade. Para os autores, a "AAA foi responsável pela emissão do principal documento produzido pela teoria da contabilidade da época, o ASOBAT, em 1966" (Silva et al., 2018, p. 31). Os pesquisadores esclarecem que o A Statement of Basic Accounting Theory (ASOBAT) discutiu alguns tópicos - por exemplo, características qualitativas, uniformidade e utilidade da informação - que acabaram sendo absorvidos por futuros documentos, tendo o período normativo papel importante para a evolução das normas do Financial Accounting Standard Board (FASB) e International Accounting Standard Board (IASB).

Vale destacar que a lista de top journals pouco mudou nas últimas décadas, assim como não houve mudança significativa nos temas publicados (gerenciamento de resultados, modelos de previsão, compensação, regulação, governança e orçamento), cenário resultante de um deturbado sistema de incentivo a pesquisadores, o qual privilegia quantidade em detrimento da inovação (Moser, 2012; Basu, 2012).

Para Hartmann (2017), o verdadeiro conhecimento contábil vai além do que se produz e discute em periódicos acadêmicos. $\mathrm{O}$ autor aponta que, embora as últimas décadas tenham apresentado crescimento nas estatísticas de artigos acadêmicos (quantitativos e qualitativos), a posição da contabilidade em relação às outras ciências não é favorável. Conforme o pesquisador, a contabilidade mais toma emprestado disciplinas de outras áreas do que oferece conhecimento para outras ciências. Assim, o saldo da balança entre contabilidade, economia, psicologia, ciência política, sociologia, neurociência e outras ciências seria negativo, com perda de espaço na academia, o que refletiria a estagnação da pesquisa contábil.

\section{CIÊNCIA E PARADIGMA KUHNIANO}

Wray (2011) afirma que a ideia de paradigma, termo popularizado por Kuhn, foi antes abordada por Bruner e Postman, os quais definiram o conceito, mas limitaram o uso do termo ao subtítulo e título resumido de um artigo publicado em 1949. Ainda, que Robert K. Merton teria usado o termo na década de 1950 em revisões literárias e artigos publicados. Ou seja, Wray 
(2011) sustenta que o termo "paradigma" já havia sido usado antes de Kuhn começar a utilizá-lo em seus trabalhos.

Na visão de Cushing (1989), a evolução do conhecimento científico, na perspectiva kuhniana, se dá em oito fases: i) pré-paradigmática; ii) desenvolvimento de consenso; iii) ciência normal; iv) crise; v) surgimento de novos paradigmas e debates; vi) revolução; vii) ciência normal; e viii) repetição das fases iv a vii. Kuhn (1962) explica que a fase pré-paradigmática seria característica das ciências jovens que ainda estavam firmando as bases do conhecimento naquela área do saber, definindo suas regras de funcionamento e pesquisa, embora os debates produzidos servissem mais para definir escolas do que para produzir um acordo.

O paradigma seria a constituição de uma visão de mundo, uma estrutura lógica sistematizada capaz de explicar determinado conjunto de fenômenos que o próprio paradigma definiria como relevantes. Embora o paradigma não explicasse minuciosamente os fatos confrontados, seria a melhor explicação em determinado momento histórico, caracterizando-se como o entendimento mais aceito entre os cientistas do campo (Kuhn, 1962).

De acordo com a teoria kuhniana, com o surgimento de uma teoria ou conjunto de teorias que explicavam determinados fenômenos e que orientariam o trabalho científico na área, criavase um paradigma e, assim, passava-se a fase da ciência normal, em que o paradigma serviria de guia para que fossem resolvidos os problemas (quebra-cabeças) daquele campo de pesquisa. À medida que pesquisadores identificavam anomalias relevantes que não se encaixavam no paradigma vigente, passava-se a buscar respostas em outras teorias ou conjunto de teorias. Instalava-se uma concorrência entre teorias, o que caracterizaria a fase de crise, também denominada fase de ciência extraordinária, que perduraria até que um novo paradigma fosse alcançado para conduzir a uma nova fase de ciência normal.

Wray (2011) afirma que, num primeiro momento, houve críticas a Kuhn e sua obra, The structure of scientific revolutions, pois o conceito de paradigmas não se mostrava muito claro. No entanto o pesquisador aponta que Kuhn esclareceu as controvérsias e articulou um entendimento mais preciso sobre o conceito de paradigma ao longo dos anos 1970 com novas publicações, tornando seus conceitos sobre paradigmas guias para pesquisas futuras.

A ideia do processo cíclico de desenvolvimento científico de Kuhn foi representada graficamente por Vieira e Fernandez (2006), destacando-se que a fase de crise ou ciência extraordinária não corresponderia a um ponto de contato ou transição pontual entre paradigmas, mas a um período de convivência entre propostas de paradigmas diferentes.

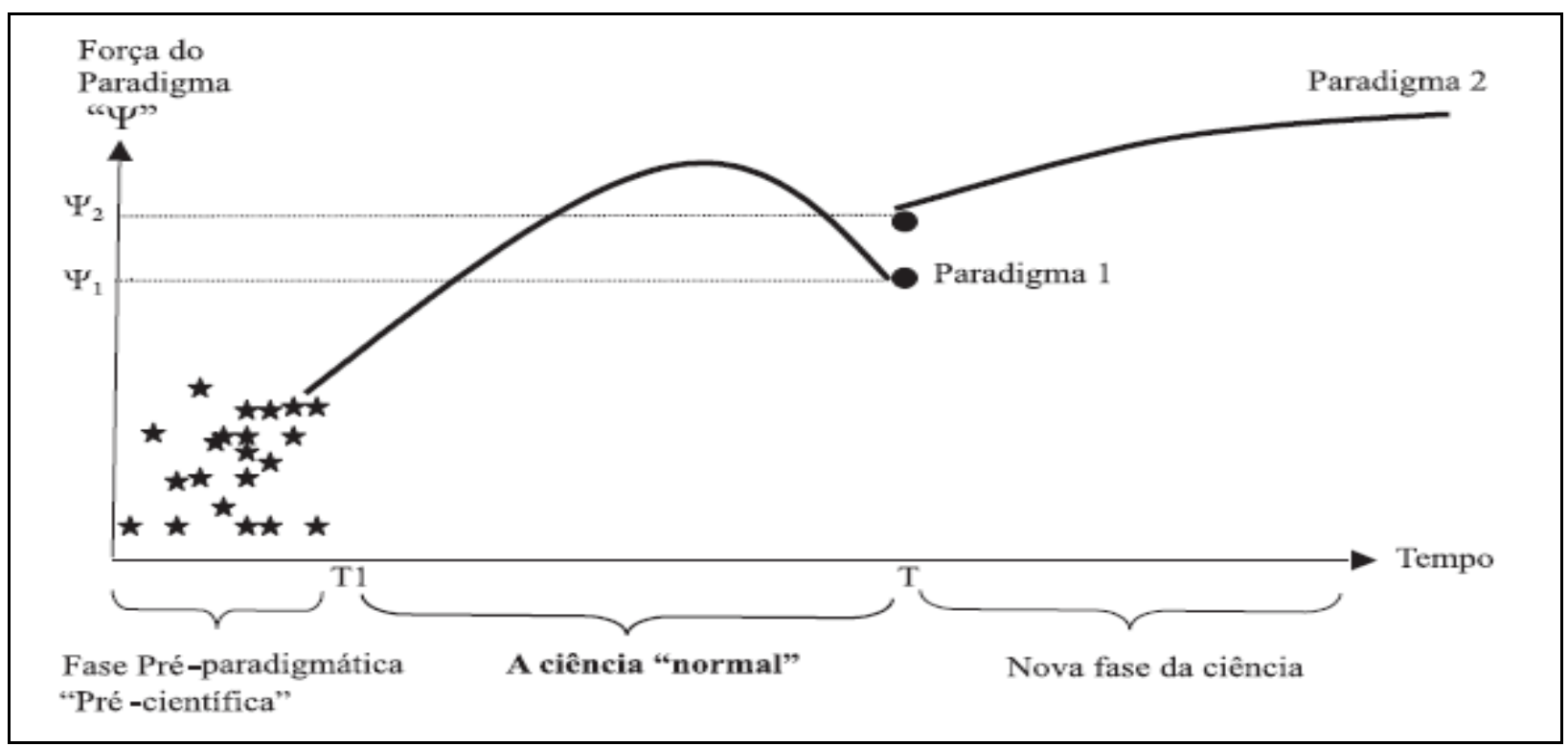

Figura 1. Processo de desenvolvimento científico kuhniano.

Fonte: Vieira e Fernandez (2006). 
A ciência avança com o aprofundamento de estudos no âmbito dos paradigmas ou, alternativamente, pela quebra de paradigmas (Kuhn, 1962). A capacidade para o aprofundamento decorre de um esforço recorrente de articulação, atualização e aplicação do paradigma em condições novas e mais rigorosas, ampliando o alcance e a capacidade de explicação da ciência normal. Esse esforço precisa ser, ao mesmo tempo, teórico e experimental. Já a quebra de paradigma e sua substituição por outro ocorre quando a teoria perde a capacidade de prover explicações convincentes para os fenômenos estudados e os cientistas não conseguem mais evitar a busca por respostas alternativas que o paradigma original não conseguiu oferecer.

Cushing (1989) defende que, embora Kuhn aparentemente acreditasse que sua teoria não pudesse ser aplicada nas disciplinas sociais, seria possível usar a perspectiva kuhniana para aprender algo útil sobre a evolução da contabilidade, não necessariamente sobre metodologia ou status, mas sobre conhecimento contábil em si.

\section{PARADIGMA CONTÁBIL E PERÍODO DE CRISE}

Para Cushing (1989), o paradigma da contabilidade surgiu com o modelo de partidas dobradas, o qual teria dominado a ciência nos últimos quatro séculos. Para o autor, o modelo das partidas dobradas evoluiu de forma muito semelhante ao que Kuhn descreve como ciência normal, pois houve, dentre outros fatores, o desenvolvimento dos livros contábeis, a evolução e extensão da prática de débitos e créditos, a criação de métodos alternativos de mensuração e a utilização do modelo por diferentes usuários. $\mathrm{O}$ autor entende também que teria se iniciado no século XX, em dois estágios, o período de crise da ciência. O primeiro momento seria decorrente do distanciamento da atividade contábil das necessidades dos usuários e sua forçada padronização/uniformização exigida pela regulação (início do século). O segundo e pior estágio da crise teria começado com a tentativa de tornar a contabilidade mais científica com a abordagem positivista (após década de 1970).

Aqui tentamos colocar outro ponto de vista, mais voltado para os séculos XX e XXI. No nosso entendimento, na esfera dos paradigmas, os debates e publicações das décadas de 1920 a 1960 indicam que estavam se firmando as bases do conhecimento na área do saber contábil, a exemplo das obras Accounting theory (Paton, 1922), An introduction to corporate accounting standard (Paton \& Littleton, 1940), Structure of accounting theory (Littleton, 1953) e The philosophy of auditing (Mautz \& Sharaf, 1961).

Já os avanços ocorridos na década de 1960 podem levar à percepção de que um paradigma surgiu naquela época, o qual buscava resolver problemas e orientar as pesquisas no futuro. Um dos elementos que sustentam esse pensamento foi a publicação pela AAA do ASOBAT em 1966, documento que encampou o desafio de concentrar em um único Statement um guia para educadores, praticantes e outros atores interessados na contabilidade.

Interessante registrar que, diante de uma lacuna conceitual, já na introdução, o ASOBAT (AAA, 1966) trouxe o que seria "teoria", ou seja, um conjunto harmômico de princípios hipotéticos, conceituais e pragmáticos, o que formaria uma base de conhecimento para determinado campo de estudo. Ainda, a AAA (1966) também conceituou contabilidade como o processo de identificação, mensuração e comunicação de informação econômica em cenários de recursos escassos, o que permite a realização de julgamentos bem informados e a tomada de decisões por usuários da informação contábil.

Vale registrar que o AICPA lançou, em 1970, o Accounting Principles Board (APB) no 4 (1970), documento que teve por pretensão estimular ainda mais a discussão sobre temas relevantes para a área contábil. O objetivo do documento era fornecer uma base para melhor entendimento dos fundamentos da contabilidade financeira e, ainda, servir de orientação para o desenvolvimento desse ramo da contabilidade.

A partir da década de 1970, estudos que relacionavam a informação contábil com o mercado de capitais por meio da avaliação do conteúdo informacional dos relatórios contábeis, 
baseados em abordagem positivista, continuavam trazendo significativos avanços para a contabilidade. Contudo Beaver (1981) afirma que esse viés neoliberal foi percebido apenas como revolução (não kuhniana) do relatório financeiro, enquanto Cushing (1989) defende que esse período representou grave indicativo de crise na ciência contábil.

Em se tratando de processo evolutivo, há de se mencionar as estruturas conceituais da contabilidade. Gornik-Tomaszewski e Choi (2018) explicam que estrutura conceitual é um sistema lógico de objetivos inter-relacionados e conceitos básicos que prescrevem a natureza, a função e os limites de um relatório financeiro, tendo como função orientar o desenvolvimento consistente da contabilidade, seja baseada em regras ou princípios.

Gornik-Tomaszewski e Choi (2018) esclarecem que o FASB publicou, entre os anos de 1978 e 2000, uma série de normas que constituíram sua estrutura conceitual inicial. Por sua vez, o IASB, à época chamado de International Accounting Standards Committee (IASC), publicou sua estrutura conceitual em 1989, a qual foi parcialmente derivada dos Concepts Statements do FASB. Os autores afirmam que ambas as estruturas conceituais foram criticadas por vários motivos, dentre eles a falta de consistência interna e pouca clareza na exposição das ideias. Ainda, que os frameworks estavam desatualizados e não refletiam por completo a contabilidade desenvolvida nas últimas décadas.

Tal evidência motivou, em 2002, a formação de um grupo com membros do FASB e IASB para o desenvolvimento conjunto de uma nova estrutura conceitual (Norwalk Agreement). O resultado desse trabalho, conforme Gornik-Tomaszewski e Choi (2018), foi a publicação, em 2010, do Statement of Financial Accounting Concepts (SFAC) $\mathrm{n}^{\circ} 8$ pelo FASB e de uma versão revisada do framework pelo IASB.

As entidades sustentam desde então que o objetivo do relatório financeiro é fornecer informações financeiras sobre a entidade que reporta, sendo essas informações úteis para investidores, mutuantes e outros credores, existentes e potenciais, na tomada de decisões quanto à oferta de recursos à entidade. Tais decisões envolveriam a compra, venda ou manutenção de instrumentos, patrimônio e dívida, bem como a oferta ou liquidação de empréstimos e outras formas de crédito (FASB, 2010; IASB, 2010, 2018).

Vale registrar que, em que pese o atual entendimento dos Boards, no passado, sinalizou-se que a contabilidade tinha como usuários dois grandes grupos: externos e internos. No que tange à informação contábil para usuários externos, o ASOBAT (AAA, 1966) destacava a composição heterogênea do grupo, constituído por investidores atuais e potenciais, credores, clientes, governo, associações de comércio, reguladores, entre outros. Para esse grupo, o foco da contabilidade deveria passar pela redução da incerteza da informação (incluindo as incertezas referentes ao uso de previsões), uma vez que usuários externos eram mais distantes da fonte das informações e não tinham acesso direto aos dados empresariais.

Adicionalmente, o ASOBAT (AAA, 1966) ainda tratava, em todo um capítulo, o uso da informação contábil para o gerenciamento interno das organizações, sendo relevante fornecer informações para pessoas de dentro das entidades a fim de permitir julgamentos informados e decisões efetivas que favorecessem os propósitos organizacionais.

No entanto, o IASB (2018) entende que apenas atuais e potenciais investidores, mutuantes e credores são os usuários primários dos relatórios financeiros, uma vez que não podem demandar que as entidades reportem informações diretamente para eles. O Board, no parágrafo 1.7 do Framework 2018, enfatiza que o relatório financeiro de propósito geral se destina a fornecer informações que auxiliem atuais e potenciais investidores, mutuantes e credores a estimar o valor de uma entidade. Já no parágrafo 1.9, o Board reconhece que a administração de uma entidade também se interessa em informações financeiras, contudo não precisa de relatórios financeiros porque pode obter essas informações internamente. Ainda, o IASB reforça que os relatórios financeiros, embora possam ser úteis, não são direcionados a órgãos reguladores e terceiros que não sejam atuais ou potenciais investidores e credores. 
Embora ainda prematuro, o Framework 2018 vem sofrendo críticas. Barker e Teixeira (2018) afirmam que a nova Estrutura Conceitual tratou de forma incompleta a questão dos accruals na contabilidade, fornecendo poucos insights sobre o tema. Para os autores, o documento discute como um ativo ou passivo contribui para o fluxo de caixa futuro e como mensurar esses elementos patrimoniais, mas não aborda o potencial informacional da mensuração de receitas e despesas. Gornik-Tomaszewski e Choi (2018) destacam que a abordagem prática em questões envolvendo mensuração e a distinção entre lucro, prejuízo e outros resultados abrangentes gerou uma mistura inapropriada de conceitos e regras.

Para Basu (2012), a pesquisa contábil está estagnada há décadas. O pesquisador entende que a estrutura conceitual de 2010 atuava como "antolhos" para os contadores, cegando os acadêmicos para importantes temas da contabilidade, especialmente aqueles não incluídos no normativo, uma vez que muitos pesquisadores (principalmente os que não possuem experiências práticas) acreditam que a estrutura conceitual resolve todos os problemas fundamentais da contabilidade.

Retornando aos pensamentos kuhnianos e buscando entender a evolução da ciência contábil, vale mencionar a pesquisa de Santos e Costa (2018) sobre a visão paradigmática na contabilidade gerencial. Os autores defendem que, no início do século XXI, Zimmerman motivou, por meio de suas pesquisas, a discussão sobre paradigmas e desenvolvimento científico na contabilidade gerencial. Porém tal motivação não se sustentou, de forma que são poucas as discussões sobre o tema na área contábil, com exceção para os trabalhos de Lukka, Malmi, Merchant e Modell publicados na Management Accounting Research em 2010.

Santos e Costa (2018) afirmam que, em geral, os pesquisadores entendem, com limitações conceituais, que na contabilidade prevalece uma visão multiparadigmática, multiteórica ou de straddling paradigm, em contraposição ao paradigma econômico que orientou isoladamente a contabilidade no século passado. Ainda, os autores concluem que a contabilidade gerencial está situada em um período pré-paradigmático, não havendo um paradigma nessa área, sendo as escolas econômica e alternativa às referências no campo gerencial.

Como forma de ampliar a discussão, este trabalho oferece reflexões no que concerne ao paradigma na contabilidade, sugerindo ser o ASOBAT (AAA, 1966) o ponto inicial do período de ciência normal. O Statement de 1966, fruto do esforço de pesquisadores norte-americanos, baseou-se nos estudos publicados nas décadas de 1920 a 1950 e teve por objetivo oferecer soluções para os problemas existentes à época, concatenando descobertas aceitas na contabilidade e orientando a comunidade sobre assuntos atinentes à ciência contábil. Ao que tudo indica, esse trabalho foi recepcionado por grande parte dos contadores, uma vez que vários pontos do documento da AAA foram novamente tratados pela AICPA no APB no 4 (1970). E mais, ao longo do tempo, os frameworks do FASB e IASB também se valeram de parte dos ensinamentos do Statement de 1966, demonstrando a importância desse documento para a ciência contábil e, por que não dizer, para o entendimento do (primeiro?) paradigma contábil.

Ainda, alinhado ao entendimento de Cushing (1989), suscita-se a hipótese de que a ciência contábil esteja em um período de crise kuhniana, ou seja, quando o paradigma deixa de oferecer soluções às questões emergentes do campo. Tal entendimento se sustenta em algumas constatações, como as críticas aos frameworks (Barker \& Teixeira, 2018; Basu, 2012; GornikTomaszewski e Choi, 2018), bem como críticas à limitação decorrente da abordagem positivista na pesquisa contábil (Major, 2017). Para Major (2017), a crítica à abordagem positivista na pesquisa contábil e ao atual paradigma estaria relacionada à numerosa replicação de estudos que não constituem contribuições efetivas à ciência. Ribeiro (2014), por exemplo, investigou a evolução da pesquisa em contabilidade em 18 anos de publicações e destacou que a pesquisa contábil ainda tem muito a evoluir. $\mathrm{O}$ autor percebeu em sua pesquisa que os estudos se limitam a verificar o cumprimento de normativos vigentes, não refletindo sobre a razão da existência de normativos e a necessidade da evolução na área. 
Isto posto, a partir do esquema de Vieira e Fernandez (2006) e com base na pesquisa exposta até aqui, oferece-se ao leitor uma proposta kuhniana para ciência contábil, focada principalmente nos séculos XX e XXI, conforme exposto na Figura 2. Embora não previsto por Kuhn (1962), optou-se por acrescentar uma fase embrionária na estrutura da revolução científica, momento que representaria o início da formação do conhecimento contábil da forma como conhecemos hoje, marcada pela obra de Luca Pacioli. No último século, o momento préparadigmático da contabilidade teria se dado nas décadas de 1920 a 1950, nascendo propriamente o paradigma na década de 1960, o qual orientou estudos e pesquisas, inclusive o desenvolvimento das estruturas conceituais (E.C.) do IASB e FASB. Por fim, acredita-se que o atual paradigma esteja em declínio, o que poderia levar a uma revolução da contabilidade e surgimento de um novo paradigma.

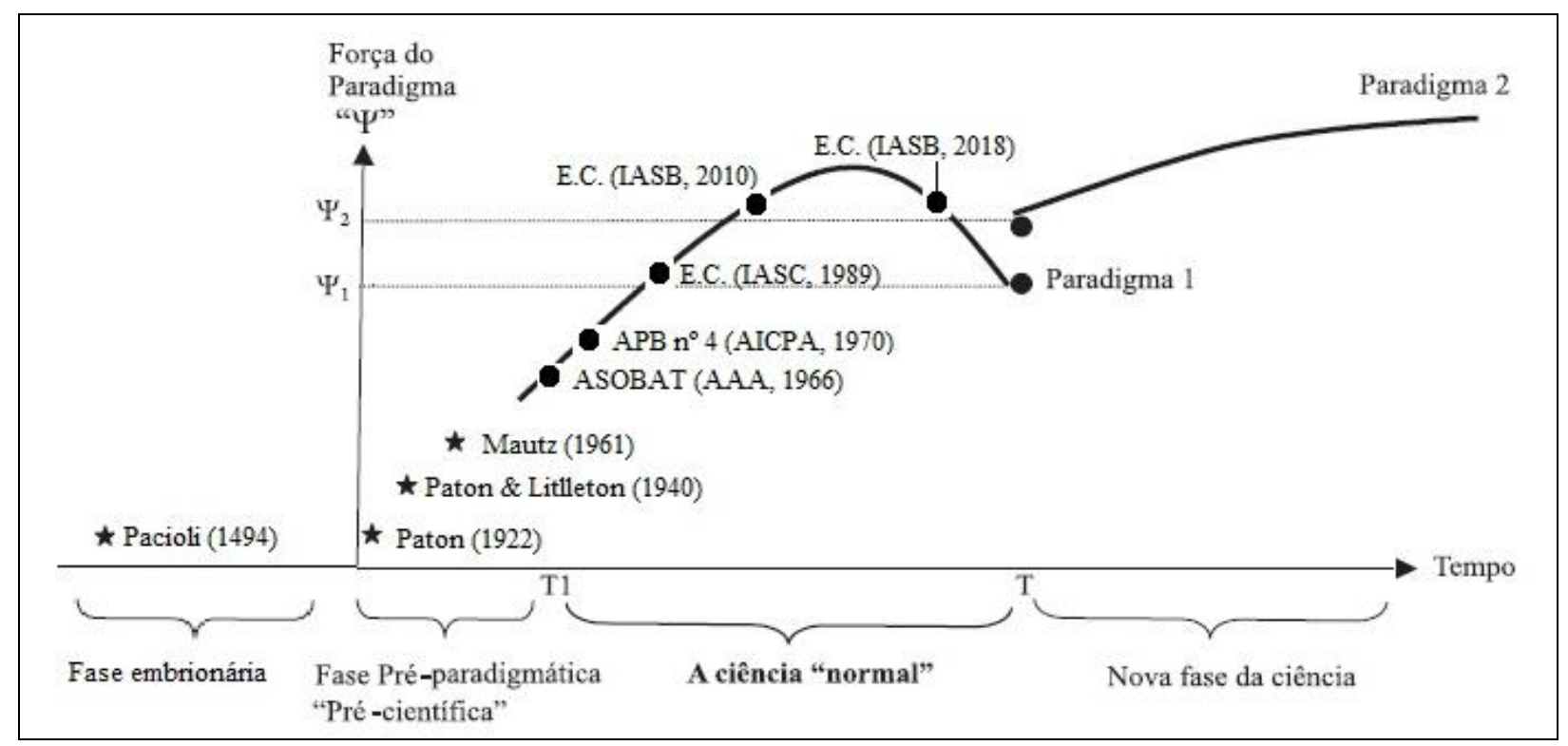

Figura 2. Processo de desenvolvimento científico kuhniano na contabilidade.

Fonte: Adaptado de Vieira e Fernandez (2006).

Não obstante, importa mencionar que, na visão de Santos e Costa (2018), no que tange à contabilidade gerencial, não há um paradigma estabelecido, sendo que a disciplina estaria hoje situada em um período pré-paradigmático. Para os autores, contabilidade gerencial ainda não encontraria reconhecimento da comunidade e necessitaria de maiores discussões em busca de um paradigma, as quais estão sendo travadas pelas escolas econômica e alternativa.

\section{NOVO PARADIGMA}

Dentre as perspectivas futuras, Cushing (1989) acreditava ser necessário maior flexibilização da contabilidade para se reaproximar dos gestores, distanciando-se da matemática e aproximando-se da administração gerencial. Outro elemento importante mencionado pelo autor seria o foco nos sistemas contábeis, os quais seriam fundamentais para extrair informações financeiras para planejamento e controle. Ainda, a (re)construção do paradigma contábil passaria pela implementação e disponibilização de uma base de dados financeiros corporativa, a qual poderia ser acessada por usuários externos e utilizada para avaliações diversas das empresas, expandindo a pesquisa empírica e retroalimentando os fundamentos da contabilidade enquanto ciência. Para o autor, a maneira de processar dados poderia levar a métodos válidos de explicação e predição de fenômenos contábeis de interesse dos usuários.

Hoje a quantidade de dados disponíveis para análise é enorme, originados dentro e fora dos limites das empresas. Bhimani e Willcocks (2014) explicam que o termo Big Data está 
relacionado ao registro em tempo real de dados gerados interna e externamente. Para os autores, isso inclui dados de transações contábeis regulares, dados de sensores em máquinas, chips em componentes, acessos na intranet corporativa, mapas demográficos, previsões meteorológicas, publicações em redes sociais, dados de áudio e vídeo, entre outros. Segars (2018) pondera que a habilidade em acessar, decodificar, estruturar e difundir dados é a força vital de uma empresa moderna.

Complementando as reflexões de Santos e Costa (2018) sobre o aspecto gerencial da contabilidade, importa citar a pesquisa de Rikhardsson e Yigitbasioglu (2018) que envolveu o tema Business Intelligence e Contabilidade Gerencial. Os pesquisadores buscaram artigos publicados entre 2005 e 2015 nos principais journals internacionais ("A" ranked journals) e concluíram pelo baixo número de publicações diante do esperado na era tecnológica em que vivemos. Para os autores, tal constatação tem como possíveis causas: i) poucos pesquisadores contábeis voltados para tecnologia; ii) pouca exposição dos acadêmicos às questões técnicas relativamente complexas do campo tecnológico, com reflexo na baixa compreensão e limitado interesse em buscar pesquisas nessa temática; e iii) tradicional estrutura acadêmica que não estimula uma abordagem cross-functional, em que contabilidade e tecnologia da informação poderiam ser associadas. Quanto ao último fator, Cabral, Siqueira e Siqueira-Batista (2011) advertem que a interdisciplinaridade no âmbito da contabilidade está praticamente restrita ao campo da economia, do direito e da educação, muito embora o aspecto multidisciplinar seja relevante para o desenvolvimento das ciências. Hartmann (2017) lamenta a posição desfavorável da contabilidade em relação às outras ciências, uma vez que mais pega emprestado conhecimento do que oferece em troca.

Gepp, Linnenluecke, O'Neill e Smith (2018) afirmam haver um distanciamento entre pesquisa e prática no que se refere à contabilidade e tecnologias de Big Data. Os autores salientam que há um custo inicial de aprendizagem das análises em Big Data, seus conceitos, modelos e técnicas, mas enfatizam que os benefícios podem ser compensadores. Gamage (2016) entende que processos sustentados por Big Data transformarão as organizações públicas nas mais diversas atividades governamentais, sendo imprescindível ter foco nas ferramentas de Big Data e nas oportunidades que surgem com as novas tecnologias.

\section{CONSIDERAÇÕES FINAIS}

O objetivo deste trabalho foi discutir a ciência contábil do ponto de vista da teoria kuhniana. Utilizou-se a estrutura da revolução científica de Kuhn (1962) para melhor entender o desenvolvimento do conhecimento contábil, navegando inclusive por aspectos dos períodos normativo e positivista. Como resultado, ofereceu-se ao leitor uma perspectiva paradigmática da contabilidade, reflexão centrada nos séculos XX e XXI, tendo como marco inicial o ASOBAT. A conclusão foi no sentido de que o paradigma atual já não atenderia às expectativas da comunidade de cientistas e, consequentemente, da sociedade, uma vez que os frameworks vigentes enfrentam críticas e se mostram distantes do paradigma inicial, especialmente no tange aos usuários da contabilidade.

Em um período de crise, é necessário ponderar por novos caminhos e soluções. Já na década de 1960, o próprio ASOBAT mencionava que a contabilidade deveria se aliar a outras disciplinas, resultando em uma nova contabilidade voltada à produção e à transmissão efetiva de informação relevante. Previa-se que os sistemas de informação contábil seriam alimentados por dados coletados de fontes internas e externas à empresa, com integração de diferentes sistemas, a fim de lidar com as múltiplas características e ramificações de todas as atividades. Em sua pesquisa, Cushing (1989) destacou que o enfrentamento do período de crise passaria pelo estabelecimento e liberação de acesso a bases de dados empresariais, fomentando o desenvolvimento de sistemas contábeis e pesquisas relacionadas. Neste trabalho, propomos 
continuidade a esse entendimento, sugerindo que o caminho para um novo paradigma passa pelo que se conhece hoje como Big Data.

Entretanto a contabilidade parece ainda não aceitar essa alternativa, envidando esforços em pesquisas positivistas e mantendo resistência a uma abordagem multidisciplinar. Destarte, entende-se que urge a necessidade de se alavancar o processo de união da contabilidade com as tecnologias disruptivas, iniciando-se um ciclo de aprendizagem em técnicas de Big Data e Data Analytics, com vistas a capacitar e dar experiência aos contadores nas suas mais diversas áreas de atuação. Embora os conceitos e algoritmos de Big Data não sejam inovadores (muitos decorrem de conhecimentos estatísticos há muito conhecidos), o contexto tecnológico atual permite avanços nunca antes obtidos, o que pode revelar informações preciosas e auxiliar a contabilidade a se (re)encontrar como ciência.

Uma oportunidade para pesquisas futuras seria relacionar contabilidade com modelos de mineração de dados, máquinas de aprendizagem, redes neurais, árvores de decisão e outras técnicas de Big Data. O aperfeiçoamento do processo de produção de informação contábil relevante com o uso de tecnologia se mostra cada vez mais pertinente e motivador, sugerindo-se alinhar prática e teoria no desenvolvimento da ciência contábil.

\section{REFERÊNCIAS}

Accounting Principles Board (1970). Statement of the Accounting Principles Board 4: Basic Concepts and Accounting Principles Underlying Financial Statements of Business Enterprises ( $\left.A P B n^{\circ} 4\right)$. American Institute of Certified Public Accountants.

American Accounting Association (AAA) (1966). Statement of Basic Accounting Theory ASOBAT. Florida.

American Accounting Association (2018). Celebration of the Century! Recuperado em 25 outubro, 2018, de http://www2.aaahq.org/AM/timeline/timeline.html

American Institute Of Certified Public Accountants (AICPA) (2012). Evolution of the profession. Recuperado em 01 setembro, 2018 de https://www.aicpa.org/about.html

Ball, R., \& Brown, P. (1968). An empirical evaluation of accounting income numbers. Journal of Accounting Research, 6(2), 159-178.

Barker, R., \& Teixeira, A. (2018). Gaps in the IFRS Conceptual Framework. Accounting in Europe, 15(2), 153-166.

Basu, S. (2012). How Can Accounting Researchers Become More Innovative? Accounting Horizons, 26(4), 851-870.

Beaver, W. H. (1968). The information content of annual earnings announcements. Journal of Accounting Research, 6(suplemento), 67-92.

Beaver, W. H. (1981). Financial reporting: An accounting revolution. Englewood Cliffs, NJ: Prentice Hall.

Bhimani, A., \& Willcocks, L. (2014). Digitisation, 'Bigdata' and the transformation of accounting information. Accounting and Business Research, 44(4), 469-490. 
Cabral, I., Siqueira, J. R. M., \& Siqueira-Batista, R. (2011). O diálogo das ciências contábeis com as ciências humanas e demais ciências sociais: uma análise da produção acadêmica do congresso USP de controladoria e contabilidade e ENANPAD (2004-2007). Revista de Educação e Pesquisa em Contabilidade, 5.

Chalmers, A. F. (1993). O que é ciência afinal? (2a ed. Tradução de Raul Filker). Editora Brasiliense.

Christenson, C. (1983). The methodology of positive accounting. The Accounting Review, 1-22.

Chua, W. F. (1996). Teaching and learning only the language of numbers - monolingualism in a multilingual world. Critical Perspectives on Accounting, 7(1), 129-156.

Cushing, B. (1989). A kuhnian interpretation of the historical evolution of accounting. The Accounting Historians Journal, 16(2), 1-41.

Financial Accounting Standards Board (FASB) (2010). Statement of Financial Accounting Concepts No. 8. USA.

Gamage, P. (2016). New development: Leveraging 'big data' analytics in the public sector. Public Money \& Management, 36(5), 385-390.

Gepp, A., Linnenluecke, M., O’Neill, T., \& Smith, T. (2018). Big data techniques in auditing research and practice: current trends and future opportunities. Journal of Accounting Literature, 40, 102-115.

Gleeson-White, J. (2012). Double Entry: How the Merchants of Venice Created Modern Finance. W. W. Norton \& Company. Nova Iorque.

Gornik-Tomaszewski, S. \& Choi, Y. C. (2018). The Conceptual Framework: Past, Present, and Future. Review of Business: Interdisciplinary Journal on Risk and Society, 38(1), 47-58.

Hartmann, F. G. H. (2017). Accounting research: between natural science and practice. Revista Contabilidade \& Finanças, 28(73), 7-10.

Hopwood, A. (2007). Whither Accounting Research? The Accounting Review, 82(5), 1365-1374.

International Accounting Standards Board (IASB) (2010). Conceptual Framework for Financial Reporting. Londres, UK.

International Accounting Standards Board (2018). Conceptual Framework for Financial Reporting. Londres, UK.

Iudicibus, S. de (2007). Ensaio sobre algumas raízes profundas da contabilidade, em apoio aos princípios fundamentais. RCO - Revista de Contabilidade e Organizações, 1(1), 8-15.

Kam, V. (1990). Accounting Theory (2a ed.). John Wiley \& Sons Inc. New York.

Khurana, R., Kimura, K., \& Fourcade, M. (2011). How Foundations Think: The Ford Foundation as a Dominating Institution in the Field of American Business Schools. Working 
paper, Harvard Business School. Recuperado em 11 agosto, 2019, de https://www.hbs.edu/faculty/Publication\%20Files/11-070.pdf

Kuhn, T. S. (1962). A estrutura das revoluções científicas (9a ed., Tradução: Beatriz Vianna Boeira e Nelson Boeira). São Paulo: Perspectiva.

Major, M. J. (2017). O positivismo e a pesquisa 'alternativa' em Contabilidade. Revista Contabilidade \& Finanças, 28(74), 173-178.

Moser, D. (2012). Is Accounting Research Stagnant? Accounting Horizons, 26(4), 845-850.

Mouck, T. (1993). The "Revolution" in Financial Reporting Theory: a Kuhnian Interpretation. The Accounting Historians Journal, 20(1).

Pierson, F. C. (1959). The Education of American Businessmen. The Journal of Business Education, 35(3), 114-117.

Ribeiro, H. C. M. (2014). Dezoito anos de produção acadêmica do campo do conhecimento contabilidade sob a ótica dos periódicos internacionais the international journal of accounting e the british accounting review/eighteen year academic production field of knowledge accounting. RACE - Revista de Administração, Contabilidade e Economia, 13(3), 1211-1240.

Rikhardsson, P., \& Yigitbasioglu, O. (2018). Business intelligence \& analytics in management accounting research: Status and future focus. International Journal of Accounting Information Systems, 29(C), 37-58.

Sá, A. L. de (2005). Doutrinas, escolas e novas razões de entendimentos na Ciência Contábil. Revista Catarinense de Ciência Contábil, 4(10), 25-34.

Santos, T., \& Costa, F. (2018). Discussão Paradigmática em Contabilidade Gerencial: Uma Crítica à Interpretação Kuhniana na Academia Contábil. Anais do Congresso Anpcont, João Pessoa, PB, 2018, 12.

Segars, A. (2018). Seven Technologies Remaking the World. MIT Sloan Management Review, 119.

Silva, J. P., Niyama, J. K., \& Noriller, R. M. (2018). Teoria da Contabilidade: Reflexões Sobre os 55 Anos de Positivismo. Revista FSA (Faculdade Santo Agostinho), 15, 27-47.

Souza, J. C., \& Beuren, I. M. (2008). A inserção da teoria das revoluções científicas de Thomas Samuel Kuhn em artigos da área contábil. Anais do Congresso Brasileiro de Custos, Curitiba, PR, Brasil.

Vieira, J. G. S., \& Fernandez, R. G. (2006). A estrutura das revoluções científicas na economia e a Revolução Keynesiana. Estudos Econômicos, 36(2), 355-381.

Watts, R. L., \& Zimmerman, J. L. (1986). Positive Accounting Theory. Prentice-Hall. New Jersey. 
Whitley, R. (1986). The Transformation of Business Finance into Financial Economics: The Roles of Academic Expansion and Changes in U.S. Capital Markets. Accouting, Organizations and Society, 11(2), 171-192.

Whitley, R. (1988). The possibility and utility of positive accounting theory. Accounting, Organizations and Society, 13(6), 631-645.

Whittington, G. (1987). Positive accounting: A review article. Accounting and business research, 17(68), 327-336.

Williams, P. F. (2017). Jumping on the wrong bus: Reflections on a long, strange journey. Critical Perspectives on Accounting, 49, 76-85.

Wray, K. B. (2011). Kuhn and the discovery of paradigms. Philosophy of the Social Sciences, 41(3), 380-397. 